\title{
CNC ROUTER WITH SCREW-NUT TRANSMISSIONS
}

\author{
M.A. PĂUN, A.A. DOROFTEI, G.A. TUDOR, I. MOLDOVAN \\ Valahia University in Târgoviște \\ E-mail: paun_marius_2009@yahoo.com, alexandru_andrei3000@yahoo.com, agheorghet@gmail.com, \\ iuli.moldovan96@gmail.com
}

\begin{abstract}
The CNC (Computer numerical control) is a machine that processes different kinds of materials at different types of precisions, determined by the system used to realize the transmission from the motor to the axes. In our project, we used the screw nut transmission because it offers a great precision and it has an optimal price-quality ratio.
\end{abstract}

Keywords: CNC, numerical control, Latte Panda.

\section{INTRODUCTION}

In order to make two or three-dimensional cuts, special automatic tools are needed so that it is possible to accelerate the material cutting process while increasing the precision of the same man-made process. One of these tools, used for cutting soft materials, such as wood, PVC or certain non-ferrous materials, is the $\mathrm{CNC}$ router [1].

A CNC router is a machine controlled by a computer and it has the role of cutting automatically. The trajectory of the cuts is controlled by a system called numerical control, which sends the coordinates of the cut from the computer with millimeter precision. The $\mathrm{CNC}$ rotors are very similar to the milling machines that have the same use, but the difference is that, by using the $\mathrm{CNC}$ routers, the human factor is virtually eliminated during the cutting process. They are very useful in making identical pieces and serial production, as they usually produce consistent and high quality work [2], [3].

\section{FUNCTIONING MODE}

\subsection{General information about the control system}

The numerical control system is a system that allows the control of the position of a physical element in three axes: $\mathrm{X}$ (length), Y (width) and Z (depth). This system can be used with any type of cutting tool that is mounted on the machine. By means of software and a set of commands, the coordinates of the position of a certain point are controlled relative to an initial position (which is $0,0,0$ for the machines). It can be perceived as a kind of GPS, but applied to mechanization, and with much more precision.

If in the case of milling machines the models were made according to technical drawings and certain details could not be created in reality, in this case (CNC routers) the limitation of the models that can be made is virtually nonexistent because it cuts in different axes. To work with the $\mathrm{CNC}$ router you only need to create the desired design in software that is compatible with numeric control programming. The CNC Router allows you to use models made in programs such as Indesign, Illustrator, AutoCAD, NxCam, FreeHand, Inventor, Sketchup codes, which makes it a language understood only by the CNC Router. The only requirement is that these patterns are projected into vectors [4-5].

\subsection{The model}

For our project we used Inkscape software to create the model. After completing the model, it has to be transformed into a special format supported by the specific programming language called g-code, so we used the www.makercam.com site. For the control of unipolar motors we have used the GRBL open source library written in the Latte Panda development board. The communication between the computer and Latte Panda was done using code sender, which is also open source software, sending the coordinates were the cutting tool arrives. The commands sent by GRBL (An open source, embedded, high performance g-code-parser and $\mathrm{CNC}$ milling controller written in optimized $C$ that will run on a straight Arduino) code to unipolar motors were made possible by using a CNC-shield and A4988 drivers.

To illustrate how it works you have to picture the image of a square in you head, each of the edges of the square has one of the coordinates. If we want to position the tip of the instrument and touch one of these coordinates, all we have to do is enter the corresponding command in code sender. Then the command will be sent by the G-code to the Latte Panda which will use GRBL to translate this command and move the tool to the indicated position.

\subsection{Units}

CNC program can be written in either Inch or Metric units. The machine can be switched with a single code to accept either.

\subsection{Equations}

The GNU program follows the fray the milling fray draws, depending on the map made of strategic points.

Starting from a certain strategic point, the distance to the second point is calculated, after that the trajectory being merged through vectorial points. The apex of a vector becomes another one's origin (Figure 1). 


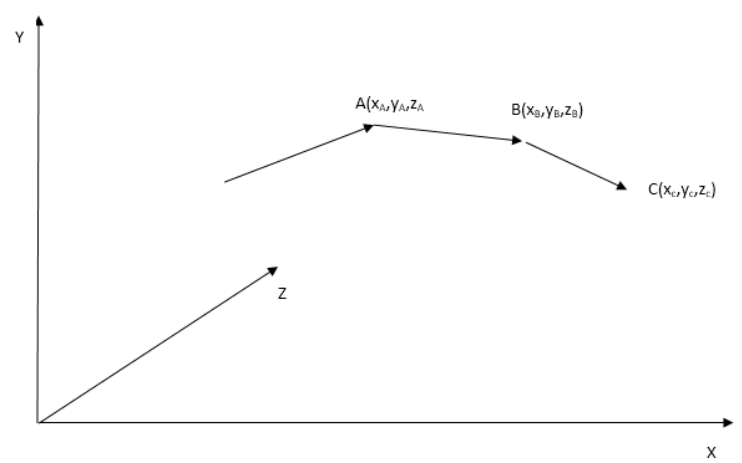

Figure 1. Vector without time versor

Every vector from Minkowski's space owns three dimensions plus the notion of time shown in Figure 2.

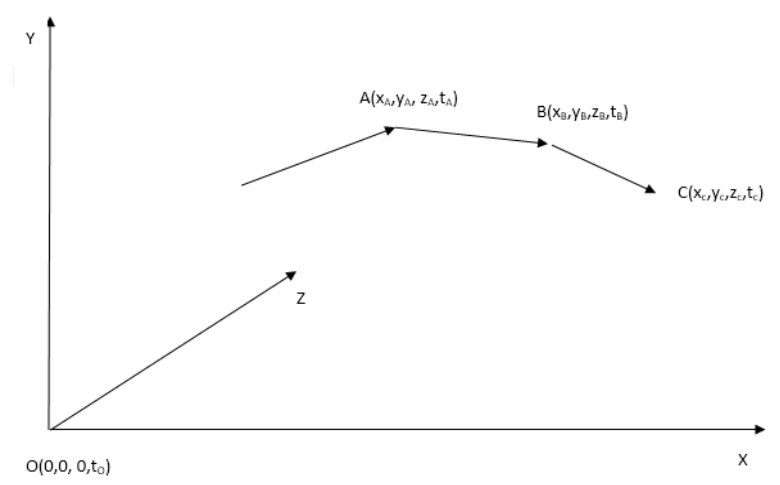

Figure 2. Vector with time versor.

And so the distance is being calculated with the following formulas:

$$
\begin{aligned}
& A B=\sqrt{\left(x_{B}-x_{A}\right)^{2}+\left(y_{B}-y_{A}\right)^{2}+\left(z_{B}-z_{a}\right)^{2}} \\
& B C=\sqrt{\left(x_{C}-x_{B}\right)^{2}+\left(y_{C}-y_{B}\right)^{2}+\left(z_{C}-z_{B}\right)^{2}}
\end{aligned}
$$

\subsection{Components}

\section{Parts:}

1. Latte Panda: this piece sends orders to the engines, basically a small computer.

This piece is a single board computer which contains an Intel Trail z8300 Quad Core $1.8 \mathrm{GHz}$ processor and a ATmega32u4 microcontroller, Arduino compatible. Using the ATmega32u4 microcontroller, sensors can be connected directly to the board exactly like on an Arduino Board (Figure 3).

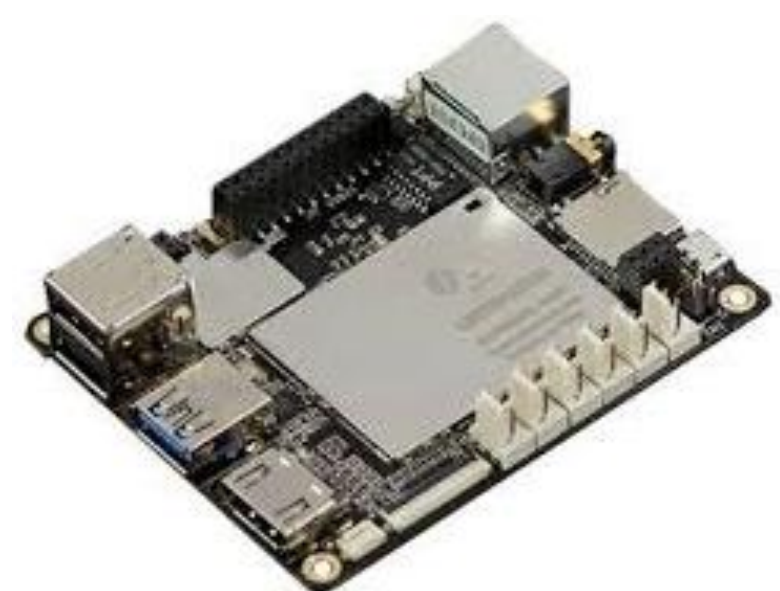

Figure 3. Latte Panda.

2. Metallic body made of an angle and a metallic skeleton, used for engine and milling system stabilization.

\section{Bearings system}

Bearings are machine parts that are used for guiding and sustaining the movement mechanism, whose orders are given by the Latte Panda.

4. Vibration reduction system made of hose part Vibration is the oscillatory or repetitive movement of an object around its main position. The main problem, however, is that when the vibrations are far too powerful, damage starts to appear on the mechanical parts, which is why their reduction was an important step in the CNC's performance.

5. Engines: 3 unipolar engines are presented in Figure 4.

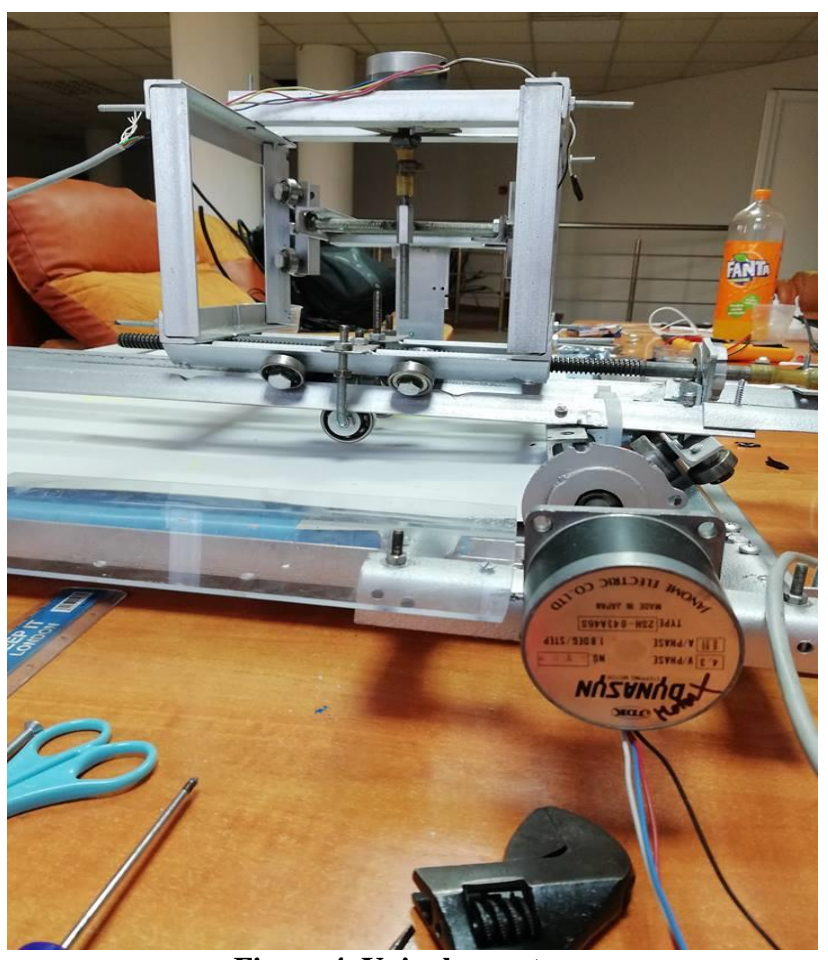

Figure 4. Unipolar motor. 


\section{Movement system built around screw-nut concept}

Threaded assemblies are demountable assemblies frequently used in car manufacturing, made through threaded parts, one threaded on the exterior and one on the interior.

The screw-nut transmissions are transmissions which, with the help of a helical coupling, connect the rotation movement intro transition movement, simultaneously orders. The helical coupling is the main part of the screwnut transmission mechanism (Figure 5).

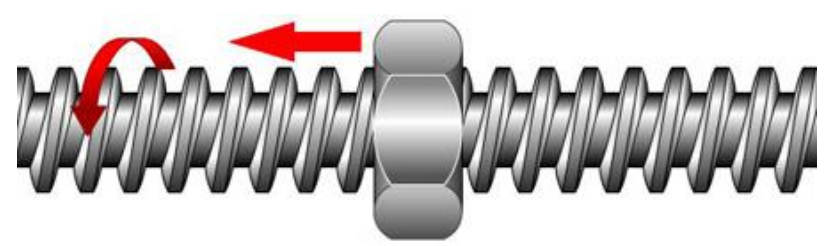

Figure 5. Movement system built around screw-nut concept.

Advantages of this type of transmission:

- powerful grip at a relatively small cost;

- can be easily assembled;

- small price due to big amounts of pieces manufacturing; - easy to commute between inches and centimeters due to the national and international standardization;

- safe while exploiting;

- reduced noise;

- low risk of malfunctioning;

\subsection{Advantages}

Advantages of Using a CNC Router:

- reduces operating errors almost to zero;

- uniformity of the products that it produces;

- scalability these cars do not need rest can produce serial production;

- one person is required to supervise CNC activities.

- as a direct result of cutting precision, it creates much less waste and also leads to exponential savings.

\section{CONCLUSION}

It can be used for milling parts, attaining final parts made of different materials like wood, iron, steel, depending on what type of extremity the milling machine uses.

If we equip the $\mathrm{CNC}$ with a laser, we are able to obtain an engraving machine, engraving patterns on wooden boards, textile materials and even iron, all of it depending on the laser's ability.

If the CNC is equipped with a chainsaw, it can cut wood with very high precision.

This type of technology is very spread throughout the industry, being very useful. The only limit of this product is the human imagination.

\section{ACKNOWLEDGMENTS}

In the making of this project we were supported by Mrs Florin Dragomir, our professor. He provided us with a workspace and necessary materials and components.

\section{REFERENCES}

[1] Sisteme tehnice cu transmisii surub-piulita. București, George Dobre, Elena Miriță, ed. Institutul Politehnic Bucuresti, 1984.

[2] Mecanisme surub piulita Indrumar de proiectare București: A.Jul, E. Chigu, Gh. Moldovean, D.Velicu, D.Savescu, Gh.Mogan ,R.Velicu,E. Eftimie,Cl. Pozna, D. Oprean, M. Lates, ed. Lux Libris, 1950.

[3] Sisteme cu şuruburi de mişcare: îndrumar de proiectare. Bucureşti, ed. Universitatea Politehnica Bucureşti, Catedra Organe de maşini şi tribologie, 1993.

[4] Understanding CNC Routers: Demystifying CNC Wood Router Technology: Alain Albert Montreal, FPInovation, 2010.

[5] Getting started with CNC: Eduard Ford San Francisco, Maker Media, 2016. 